\title{
Bob, LitTle Jim, BLuebotTle, AND The ThreE StoogeS
}

\section{STEPHEN DAVIES}

\section{UNIVERSITY OF AUCKLAND}

Bob Solomon enjoyed humor, a good laugh. He was not a teller and collector of jokes or of humorous stories, as Ted Cohen and Noël Carroll are. He did not cultivate clever witticisms. Rather, his interest was in viewing life's contingency and absurdity for the humor that can be found there, and the target of this humor was as likely to be himself or his friends as it was to be strangers.

Bob also displayed philosophical courage. He once argued before an incredulous audience of philosophers that the Three Stooges are funny, and admitted unashamedly to being a life-long devotee.

In the published version of that talk ${ }^{1}$ he observes: "few adults in their chosen professions would dare attempt a Stooges gesture at risk of being terminally dismissed, but most men carry the secret knowledge around with them, and, in a wild fit of catharsis, display a tell-tale Stooges gesture when the door closes and the boss is out of view. I only hesitate to suggest that it is one of the most basic bonds between men, and perhaps the fact that it mystifies and sometimes horrifies women is far more elemental than the mere phrase 'a sense of humor' could ever suggest", 3

The Stooges, Bob goes on to argue, provide a challenge for the prevailing theories of humor. Of course, the point of this reductio is to demonstrate that these theories are inadequate to capture the comedy of the Stooges, not to show the Stooges aren't genuinely funny. The Superiority theory, according to which we laugh at others' weaknesses and inferiority, fails because, though the Stooges made themselves lowly

\footnotetext{
Solomon (1996).

2 Solomon (1996), p. 605.

3 Ted Cohen tells me that a general wisecrack has been "What's the difference between men and women?" "Men like the Three Stooges."
} 
and ridiculous, we do not laugh at them as a result of regarding them as beneath us. "One doesn't walk away from the Stooges feeling superior, rather released and relieved". ${ }^{4}$ The Relief theory, according to which we vent our resentment through laughter, is also unapt for the Stooges. "We laugh because the Stooges do what we would like to do, act as we would like to act ... as fools, clowns beyond humiliation, humiliating those who we too would love to humiliate". 5 The Incongruity account, according to which humor is generated by bringing disparate ideas into an unexpected juxtaposition, also fails to apply here, because it "does not explain why the Stooges get better with repetitive viewing, and why imitation is part and parcel of Stooges spectatorship. It also sells the Stooges short, prettifies their humor and ignores or denies its bite. The humor of the Stooges is the humor of mutual humiliation". 6

At this point, someone might argue that "mutual humiliation" is not an appropriate object for humorous laughter. Someone who laughs at that shows a kind of moral defect, not merely a taste that one does not happen to share. Bob avoids this concern, however, by giving "mutual" such a broad scope that it includes the audience. The result is his Inferiority theory of humor:

"laughter as the great leveler, beyond contempt or indignation, antithetical to pretention and pomp. Sitting on the sofa watching Malice in the Palace for the twenty-seventh time, we allow ourselves to fall into a world of miniature mayhem that allows us to feel as foolish as they are. ... [If we try] to avoid the supposed bad taste of enjoying the Three Stooges we encounter the much greater danger of taking ourselves too seriously".

As regards Bob's Inferiority theory of humor, I think it's right. We can't help taking ourselves seriously, both at the individual level and as regards the existence of our species. Our thoughts, achievements, and projects seem so important they inevitably structure our view of the world and of our place in it. Sometimes optimistic beliefs in gods help bolster the assumption that we are bringers of meaning to the universe. And most of the time it does not occur to us to interrogate the galactic standing of our values and commitments. Yet occasionally the absurd unlikelihood and triviality of this egocentric, anthropocentric perspective dawns on us. We see both the arrogance

\footnotetext{
Solomon (1996), p. 608.

Solomon (1996), p. 608.

Solomon (1996), p. 609.

Solomon (1996), p. 609.
} 
of our irritating colleague and the irritation we feel at his arrogance for what they will count millennia from now. Then, it is more appropriate to respond with deflationary laughter than to see ourselves as the victims of grand tragedy. If there is a plot to the universe, we are dispensable bit-players, not the stars at the head of the bill.

Still, to draw this lesson from contemplation of the Three Stooges probably requires a level of identification and engagement that Bob was positioned to have better than most of us. He was the eldest of three brothers, all of whom enjoyed the Stooges. With them, Bob could endlessly rehearse the gestures, nose-twists, eyepokes, punches, slaps, screams, and protests.

In any event, it's not my goal to defend Bob's taste in humor or the theory he proposes. Instead, I want to take up a matter I raised with him when we discussed drafts of his paper. I drew his attention to the comedic power of the repeated catchphrase; in particular, of Little Jim's "He's fallen in da water!" from the Goon Show. ${ }^{8}$ Bob took two ideas from our discussion — ritual in repetition and the set-upbut I do not think he captured all that is of interest.

The first idea concerns the ritualistic nature of serial humor and of engagement with it. Bob describes the behavior of the three stooges as "ritual humiliation" and he refers to "Moe's ritualized double eye-poke, Curly's equally practiced hand block and Moe's counter-feint". ${ }^{10}$ As we have already noted, he also comments on watching Malice in the Palace for the twenty-seventh time. The content of serialized humor sometimes exploits a formulaic predictability. And when particular episodes are obsessively re-watched by the aficionado, it is common for every word, inflection, action, and detail to be memorized.

\footnotetext{
8 This catchphrase did not become established until the seventh series. It was used by Little Jim in some earlier series, but it was not inevitably spoken when a character plonked into the water. In the fifth and sixth series, it is often Bluebottle who falls in the water and comments on this. (At www.thegoonshow.net/characters.asp, Bluebottle is described as a "young, lustful boy scout with a squeaky voice who normally gets blown up in each episode. He is often a companion of Eccles and is willing to help anyone for sweets, although he frequently fails. Bluebottle is noted for using tools or weapons made from cardboard and string. He often reads his stage directions out loud and is always greeted with a deliberate round of applause from the audience.") For instance, in Forog, Bluebottle responds with: "You rotten swine, you! You have directed me into the dreaded water and I cannot see for the fog, so I don't know whether I'm drowning or not! Shouts "Help" just in case... Help Just In Case! Lights match to see if feet are touching the bottom... No, but the legs are! Tee-Hee! I made a little jokul! Hee-hee-hee!" In The Great White Box of Barfield, he says: "Oyyyy! I'm drownded in the dreaded water. Look! All the silver paper's come off my cardboard cutlass. My best trousers is wetted This means I'll have to wear Mum's old drawers while they dry. Heeheeheee! Exits left to hear Ray Ellington's Quinten.” In Napoleon's Piano, he cries: “Aiiooo! Help! I'm in deep dreaded drowning-type water."

9 Solomon (1996), p. 606

10 Solomon (1996), p. 607.
} 
This demonstrates how an element in the experiences of serial (or of repeatedly watched) comedy is the enjoyment and comfort of the familiar and expected. As well, catchphrases or repeated bits of action become code or a secret sign, recognition of which creates a fandom community. As an element in this theme, Bob and I discussed how catchphrases can be used to promote continuity within an episode comprised of disparate sketches or to unify various episodes in a series. Consider: "And now for something completely different" (used to segue between skits in Monty Python) or "Just like that!" (as another of the magic tricks that served as background to Tommy Cooper's banter fails). But none of this tells us about humor as such, because such catchphrases are not necessarily funny or laughed at. Often they underline the humor that has passed or prime us for the humor to come.

The second idea is mentioned only passingly by Bob when he describes "a foolish and frustrated Curly carrying a block of ice up fifteen flights on a hot summer day". ${ }^{11}$ Bob does not even bother to make explicit the outcome: we realize when we first see Curly struggling under its weight that, by the time the ascent is completed, the block will be reduced to a damp cube.

Let's call this mode of humor the set-up. You know the scene. A keystone-copsstyle chase has begun and the camera cuts to two men carrying a large pane of glass. Views of the ongoing chase are occasionally interrupted by further shots of the glasscarriers as they progress cautiously through the streets. As we know from the outset, at some point the chase will pass between the glass-carriers and the pane of glass will be blasted (harmlessly) to smithereens. And when it does happen, as we know it is bound to, we laugh.

The set-up counts against the Incongruity theory-we know what is going to happen - and does not match the Superiority theory—we do not feel superior to the glass-carriers. At first sight it might be thought to match the Relief theory, because we anticipate what is to come and the tension is dissipated when the expected finally occurs. This, though, is not what is usually intended under the Relief theory, which characterizes humor as malicious delight taken in others' misfortunes (Schadenfreude), with the relief coming from the thought that it is they, not we, who suffer. Whereas, when we laugh as the pane of glass is broken, we are not laughing at the misfortune of the glass-carriers but rather at the absurdity of the situation, at the

11 Solomon (1996), p. 607. 
law-like inevitability with which chaotic mayhem sucks in bystanders and leads to (small-scale) disaster. Indeed, this case nicely fits Bob's Inferiority theory: yet again, people's best-laid plans are thwarted by the brute, irregular contingency of it all.

I think Bob regarded the funny catchphrase as a special case of the set-up. But the set-up is not a good model for the funny catchphrase. The catchphrase is not prefigured in the same way. With the set-up, there is an accumulation of tension as we draw inexorably to the unavoidable pratfall or cock-up, but this structure can be absent from the catchphrase. In Goons shows, there is a more or less unheralded "kersplash" sound effect followed by the silly, juvenile voice of Little Jim, a character who usually does and says nothing else: "He's fallen in the water!" And we laugh.

So, why are some catchphrases funny-he's fallen in the water-where othersand now for something completely different—are not? Consider the catchphrases of Bluebottle, another Goon Show character: "Enter Bluebottle, waits for applause... Not a sausage", "I don't like this game", and sometimes shortly after the previous one, "You rotten swine, you deaded me". At least for these, Bob's Inferiority theory is again relevant to their funniness. But that does not address their comic status as catchphrases, as tags that return in every episode.

There are two points to make: Unlike the unfunny catchphrases, which are no more than familiar links, the humorous ones return as welcome friends. They inherit a humorous inertia from their past uses, just as established comic characters and running gags do. (This applies also to the ritualized, which is to say stereotyped, humor of the Stooges, of course.) The second is this: catchphrases that make us laugh involve a form of meta-humor. They make a contribution to the plot or characterization on each occasion of their use, but we also recognize and appreciate the fact that they are to be woven seamlessly into each and every new episode. They draw attention to the author and his contrivance of the story. In other words, they are funny in part because they refer to the art of humor by exemplifying a funny thought and the manner of its creation and amplification. 


\section{REFERENCES}

Solomon, R. C. (1996). “Are the Three Stooges Funny? Soitanly!” In K. Higgins (ed.) Aesthetics in Perspective. (New York: Harcourt Brace \& Company): pp. 604-10. 